\title{
Metodologia inédita para medida da torção ocular reflexa
}

\author{
New metodology tomeasureocularcounterrolling
}

\author{
Ronaldo Boaventura Barcellos ${ }^{1}$ \\ Carlos Alberto Rodrigues Alves ${ }^{2}$ \\ Luiz Eduardo M. Rebouças de Carvalho ${ }^{3}$ \\ Eric Pinheiro de Andrade ${ }^{4}$
}

\begin{tabular}{|l|}
\hline RESUMO \\
\hline Objetivo: Desenvolvimento de metodologia para avaliar a torção \\
ocular reflexa. Métodos: Modificações no ceratômetro de Hemholtz. \\
que permitem a avaliação da ceratometria de ambos os olhos na \\
posição primária do olhar e durante as inclinações laterais da cabeça, \\
para a direita e para a esquerda a 30 graus. Foram examinados um total \\
de 16 pacientes e 32 olhos com astigmatismo refracional de 0,50 a 3,50 \\
dioptrias (média de $1,18 \pm 0,61)$. Resultados: Registrou-se intorção \\
reflexa semelhante no olho direito e esquerdo (5,22 $\pm 3,91$ para olho \\
esquerdo e 5,31 \pm 4,23 para olho direito). O mesmo ocorreu com os \\
valores de extorção reflexa (7,84 $\pm 4,79$ para olho esquerdo e $7,78 \pm$ \\
4,09 para olho direito). Conclusão: As modificações no ceratômetro \\
de Helmholtz permitiram a observação e quantificação da torção \\
ocular reflexa em pacientes com astigmatismo, através de metodologia \\
inédita e de fácil reprodutibilidade.
\end{tabular}

Descritores: Astigmatismo; Reflexo vestibulo-ocular; Movimentos oculares; Torção ocular; Técnicas de diagnóstico oftalmológico; Relato de caso

\section{INTRODUÇÃ̃O}

A torção ocular classifica-se em verdadeira e falsa ${ }^{(1)}$. A torção verdadeira é a rotação do olho ao redor do eixo visual. A torção falsa é a observada quando o olho está numa posição terciária (oblíqua). Para melhor compreensão desse fato, imaginemos dois meridianos na face anterior da córnea, um horizontal e outro vertical. Assim sendo, partindo da posição primária do olhar para uma posição terciária, ter-se-á a impressão de que a cruz formada pelos meridianos, rodou (Figura 1), o que na verdade não ocorre. Tal fato não seria observado num sistema de referências esférico no qual o observador se deslocasse acompanhando o movimento do globo.

A torção verdadeira não é um movimento voluntário, mas pode ocorrer fisiologicamente em determinadas circunstâncias. Diversos autores ${ }^{(2-4)} \mathrm{ob}-$ servaram que as posições terciárias extremas são acompanhadas de torção verdadeira. A convergência também é acompanhada de rotação. Para cada 10 graus de convergência ${ }^{(5)}$ registraram 1 grau de extorsão.

A primeira referência a torção ocular reflexa foi creditada a Hunter* em $1786^{(6)}$ quando, diante do espelho, notou movimento rotacional dos olhos durante inclinação lateral da cabeça Em 1866, Javal**(6), observou uma redução de acuidade visual com seus óculos para astigmatismo, quando inclinava a cabeça lateralmente. Durante certo período houve dúvida

\footnotetext{
* Hunter (1786) apud Kushner BJ, Kraft S. Ocular torsional movements in normal humans. Am J Ophthalmol 1983;95:752-62

** Javal (1866) apud Kushner BJ, Kraft S. Ocular torsional movements in normal humans. Am J Ophthalmol 1983;95:752-62.
}

Hospital Nossa Senhora da Penha - de 1997 a 1998. logia e Otorrinolaringologia da da Faculdade de Medicina da Universidade de São Paulo, assistente voluntá-
rio do departamento de Oftalmologia da Faculdade de Ciências Médicas da Santa Casa de São Paulo. oftalmologia do Departamento de Oftalmologia e Otorsidade de São Paulo.

${ }^{3}$ Médico com mestrado pela Universidade Federal de São Paulo (Escola Paulista de Medicina), Assistente do Departamento de Oftalmologia da Santa Casa de São Paulo.

${ }^{4}$ Médico Assistente Voluntário na Faculdade de Medicina da Universidade de Santo Amaro.

Endereço para correspondência: R. Joaquim Antunes, 135/701 - São Paulo(SP) CEP 05415-010. E-mail: barcelos. ops@terra.com.br 


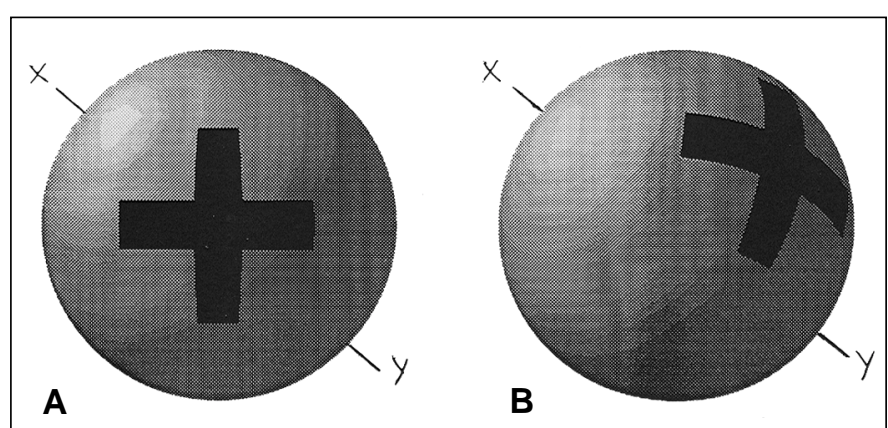

Figura 1 - A: apresenta uma representação do globo ocular com um meridiano vertical e outro horizontal no polo anterior. B: mostra a posição do globo obtida após a rotação ao redor do eixo X. Observa-se que a cruz parece ter sofrido torção.

quanto à existência ou não de uma rotação ocular compensatória, o denominado reflexo óculo-vestibular ${ }^{(1,7-8)}$ questionaram a existência deste reflexo. Atualmente está comprovado que, quando a cabeça é inclinada para um lado, produz-se de imediato um movimento dos olhos no sentido oposto. Se houver inclinação para a direita, os estímulos gerados no sistema vestibular desencadeiam extorção do olho esquerdo pela contração do reto inferior e oblíquo inferior e intorção do olho direito pela contração do reto superior e oblíquo superior. Mecanismo inverso ocorre quando a inclinação se dá para a esquerda ${ }^{(1)}$. A torção máxima é obtida com inclinação da cabeça pelo menos 30 graus $^{(9)}$.

Inúmeras técnicas foram desenvolvidas para a verificação e quantificação da torsão ocular de formas objetivas ou subjetivas.

As técnicas subjetivas são baseadas nas informações do paciente. Kushner e Kraft, descreveram a mudança do eixo do cilindro na armação de prova em pacientes astigmatas durante a inclinação da cabeça ${ }^{()}$. Outro método descrito por estes autores baseia-se na projeção de pós-imagem com a forma de cone vertical em um dos olhos, enquanto o outro olho fixa no foco de luz através do cilindro de Maddox colocado em armação de prova.

Consegue-se produzir, portanto, a imagem de uma linha vertical vermelha que fica superposta à pós-imagem do outro olho. É então solicitado ao paciente que rode o cilindro de Maddox para superpor as duas imagens durante a inclinação da cabeça. A diferença obtida nos posicionamentos do cilindro (na PPO e na inclinação lateral) é igual a quantidade de torção reflexa ${ }^{(6)}$.

Os métodos objetivos baseiam-se na observação direta do que ocorre com parâmetros facilmente identificáveis na superfície do olho (córnea, conjuntiva bulbar), íris ou retina, com relação ao referencial externo fixo, durante a inclinação lateral da cabeça. O registro destes parâmetros é feito por fotografias à biomicroscopia (córnea, conjuntiva e íris), retinografias e, mais recentemente, imagens de vídeo ${ }^{(9-10)}$.

Considerando-se a limitação intrínseca aos métodos subjetivos que é a de depender da informação do paciente e a dificuldade técnica dos outros métodos já descritos, o objetivo deste trabalho é descrever e aplicar um novo método, de execução simples e fácil reprodutibilidade para quantificar a torção ocular reflexa de forma objetiva.

\section{MÉTODOS}

\section{Pacientes}

Selecionaram-se 16 pacientes com exame de motilidade ocular normal e idade variando de 10 a 41 anos(média de $28 \pm 12,03$ ) sendo 9 homens e 8 mulheres, num total de 32 olhos. Todos eram portadores de astigmatismo nos dois olhos entre $0,25 \mathrm{e}$ 3,50 dioptrias cilíndricas (média de 1,18 $\pm 0,61$ ) com acuidade visual de 20/20 nos dois olhos. Os pacientes apresentavam boa colaboração para o exame e foram orientados quanto aos procedimentos a serem realizados, assinando termo de concordância devidamente aprovado pela comissão de ética do hospital.

\section{Descrição do equipamento}

O método utilizado baseia-se nas ceratometrias obtidas na posição primária do olhar e nas inclinações laterais da cabeça para a direita e para a esquerda. Para obter estes valores foram feitas as seguintes adaptações no ceratômetro de Helmholtz (modelo Bausch \& Lomb):

- A queixeira, que está acoplada ao aparelho, foi substituída por outra fixa na mesa.

- Desenvolveu-se uma articulação na base da queixeira que permite a sua inclinação lateral.

- À frente da articulação colocou-se um transferidor que permite a observação do grau de inclinação.

- A fixação da queixeira foi feita sobre duas hastes metálicas de $40 \mathrm{~cm}$ paralelas entre si que permitem deslocamento horizontal da queixeira para que os olhos fiquem sempre posicionados em frente ao ceratômetro.

- O anteparo no qual é posicionada a testa é arredondado. $\mathrm{Na}$ altura das têmporas fixou-se um longo parafuso de ambos os lados com um pino plástico na extremidade de tal forma a impedir o deslocamento horizontal da cabeça em relação à queixeira.

- A articulação possui um ponto de parada a 30 graus de inclinação para a direita e a 30 graus para a esquerda. (vide foto abaixo).

\section{Metodologia}

Após a refração e o exame fundoscópico os pacientes foram posicionados na queixeira na posição primária do olhar. Os pinos laterais foram fixados nas têmporas e a queixeira foi deslocada horizontalmente para que o olho a ser examinado estivesse exatamente em frente ao ceratômetro. Foi realizada a ceratometria deste olho, inicialmente sem inclinação da cabeça e a seguir com inclinações laterais direita e esquerda de 30 graus. Cuidou-se em manter a centralização do olho através do deslocamento horizontal da queixeira e do movimento vertical do próprio ceratômetro. Este mesmo procedimento foi repetido no olho contralateral. Os dois olhos permaneceram abertos durante o exame. As leituras das torções oculares, foram feitas 20 segundos após a inclinação da cabeça.

Utilizou-se para análise estatística o teste $t$ de Student para 
amostras pareadas com nível de significância de $5 \%(\alpha=0,05)$. A escolha deste teste se deveu ao fato de se tratar de uma amostra pequena e ao fato de haver uma correlação entre as medidas de extorção e intorção no mesmo olho e entre os dois olhos para um mesmo indivíduo.

\section{RESULTADOS}

O quadro 1 apresenta as medidas de extorção e intorção para o olho direito. A média de extorção foi de 7,78 $\pm 4,09$, intorção de $5,31 \pm 4,24$ graus. A análise estatística revelou um $\mathrm{p}=0,178 \mathrm{com}$ um $\alpha$ de 0,05 (5\%). Conclui-se portanto que não houve diferença estatisticamente significante entre as medidas de extorção e intorção. Em parte, estes resultados se devem à grande variação dos resultados com um desvio padrão alto.

O gráfico 1 mostra a comparação entre a média de extorção e intorção do olho direito.

O quadro 2 apresenta as medidas de extorção e intorção para o olho esquerdo. A média de extorção foi de 7,84 $\pm 4,79$, intorção de 5,22 $\pm 3,91$ graus. A análise estatística revelou um $p=0,068$ com um $\alpha$ de $0,05(5 \%)$. Não há portanto uma diferença estatisticamente significativa entre extorção e intorção para o olho esquerdo, resultado que também pode ser explicado devido aos grandes desvios padrões.

O gráfico 2 mostra a comparação entre a quantidade de extorção e intorção do olho esquerdo.

Uma análise comparativa entre os dois olhos não revelou diferenças significativas quanto à intorção $(\mathrm{p}=0,967)$ e à extorção $(p=0,941)$.

\section{DISCUSSÃO}

Jampel descreve a torção ocular reflexa como produto de artefatos de medida ${ }^{(8,11)}$. Um desses artefatos seria a não utilização de aparelhagem esférica para o registro dos movimentos

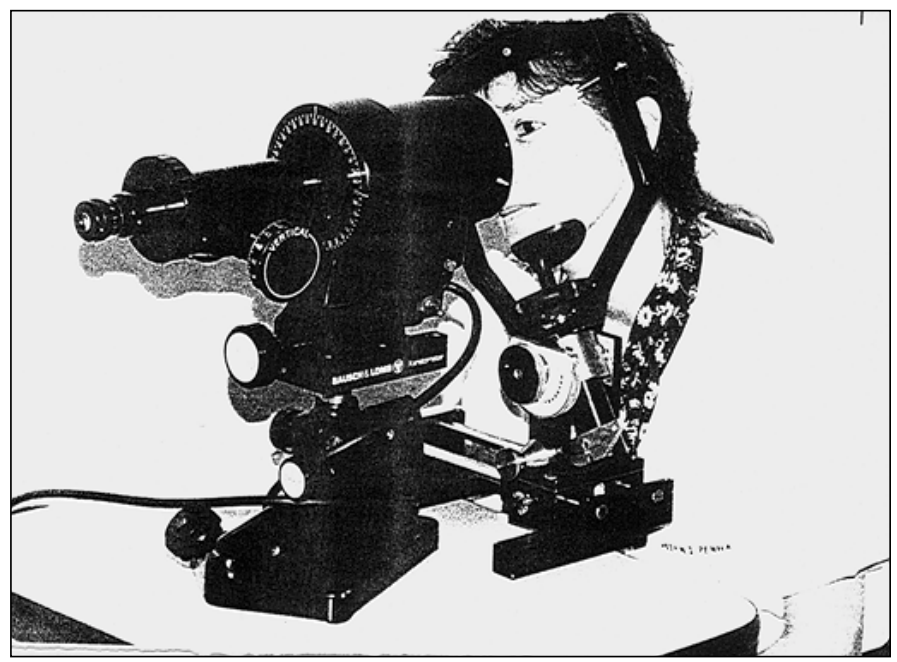

oculares, o que induziria a observação da falsa torção. Outro artefato seria ocasionado por controle inadequado da posição do olho durante a inclinação da cabeça permitindo que este assuma posição oblíqua que é acompanhada fisiologicamente de torção. Desta forma não se estaria registrando torção reflexa e sim torção secundária ao posicionamento inadequado dos olhos ${ }^{(8,11)}$.

Observou-se que a torção reflexa não ocorre linearmente ${ }^{(10)}$. Há, de início, uma rotação compensatória grande mas que vai cedendo através de pequenos movimentos torcionais sacádicos no sentido da inclinação, reduzindo a magnitude da torção reflexa resultante. Esta torção seria nula segundo alguns trabalhos ${ }^{(8,11)}$. Argumenta-se, no entanto que este resultado poderia decorrer do fato do aparato de observação se deslocar com o olho, não havendo a percepção visual da rotação, o que reduziria o estímulo indutor do reflexo ${ }^{(6)}$.

Para evitar o inconveniente da torção induzida pela ducção ocular, a queixeira do equipamento empregado nesta pesquisa

Quadro 1. Quantidade de extorção e intorção do olho direito após inclinação lateral da cabeça respectivamente para a direita e para a esquerda de $\mathbf{3 0}$ graus

\begin{tabular}{|ccc|} 
& Extorção OD & Intorção OD \\
1 & 7 & 1 \\
2 & 7 & 9 \\
3 & 4 & 15 \\
4 & 9 & 0 \\
5 & 5,5 & 3 \\
6 & 10 & 2 \\
7 & 5 & 10 \\
8 & 13 & 7 \\
9 & 6 & 4 \\
10 & 14 & 6 \\
11 & 16 & 0 \\
12 & 0 & 5 \\
13 & 5 & 6 \\
14 & 9 & 3 \\
15 & 9 & 3 \\
16 & 5 & 11 \\
\hline
\end{tabular}

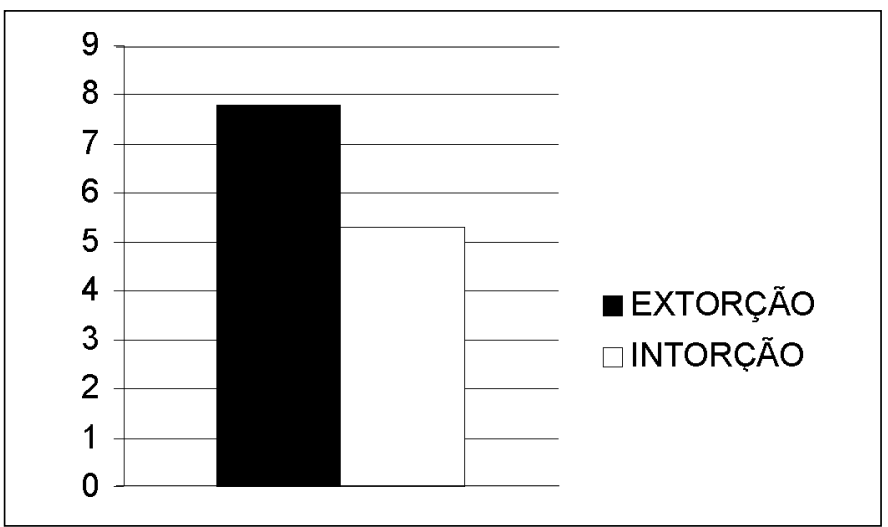

Gráfico 1 - Média em graus da extorção e intorção do olho direito 
permite deslocamento horizontal de $30 \mathrm{~cm}$ o que possibilita que o olho observado esteja sempre em frente à zona óptica do ceratômetro sem que este precise ser rodado. Desta forma o paciente estará sempre olhando em frente e não terá de procurar o ceratômetro, movimentando os olhos.

Do ponto de vista da execução do exame convém destacar que a precisão da inclinação lateral da cabeça é fundamental. Para tanto a queixeira permite a fixação automática da inclinação lateral de 30 graus para a direita e para a esquerda. $\mathrm{O}$ correto posicionamento da cabeça em relação à queixeira é reforçado com o emprego dos pinos ajustáveis que impedem o deslocamento lateral da cabeça.

Os valores de extorção não apresentaram diferenças significativas entre o olho direito e o olho esquerdo $(7,84 \pm 4,79$ para OE e 7,78 $\pm 4,09$ para OD) o mesmo ocorreu com a intorção (5,22 $\pm 3,91$ para OE e 5,31 44,23 para OD). Os valores médios obtidos são semelhantes aos registrados por Kushner e $\mathrm{Kraft}^{(6)}$, que observaram extorção e intorção média de 7 graus sem diferenças significativas entre os dois olhos. Apesar do resultado, em média, ser semelhante aos aferidos por outros autores, o desvio padrão foi alto o que dificulta as análises comparativas. Esta variabilidade poderia estar relacionada ao

\begin{tabular}{|ccc|}
\hline $\begin{array}{c}\text { Quadro 2. Quantidade de extorção e intorção do olho esquerdo } \\
\text { após inclinação lateral da cabeça respectivamente para a } \\
\text { direita e para a esquerda de }\end{array}$ \\
30 graus \\
Extorção OE & Intorção OE \\
1 & 11 & 2 \\
2 & 14 & 2,5 \\
3 & 8 & 9 \\
4 & 2,5 & 5 \\
5 & 10 & 9 \\
6 & 0 & 0 \\
7 & 4 & 6 \\
8 & 5 & 5 \\
9 & 14 & 0 \\
10 & 10 & 14 \\
11 & 8 & 5 \\
12 & 0 & 0 \\
13 & 7 & 3 \\
14 & 16 & 8 \\
15 & 6 & 8 \\
16 & 10 & 7 \\
\hline
\end{tabular}

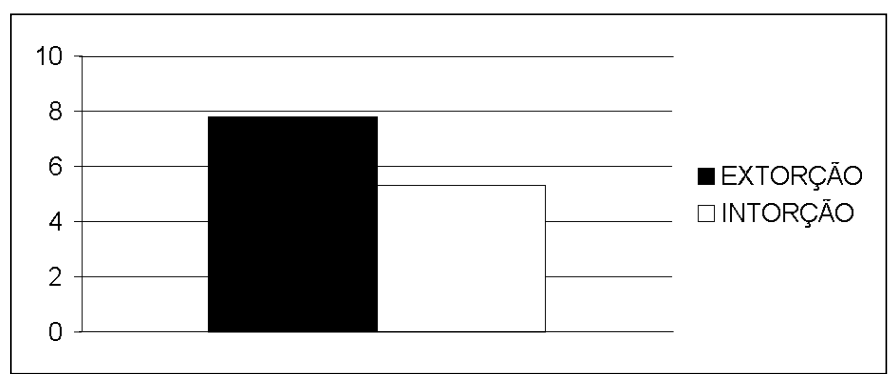

Gráfico 2 - Média em graus da extorção e intorção do olho esquerdo tamanho da amostra e àqueles pacientes que possuem astigmatismo pequeno o que reduziria a sensibilidade das medidas. Cabe ressaltar que o paciente 6 apresentou astigmatismo refracional mas não corneano o que justifica a ausência de torção no exame. Neste sentido talvez seja preferível o estudo das torções oculares com o emprego do ceratômetro naqueles casos que apresentem graus médios ou altos de astigmatismo corneano regular.

\section{CONCLUSÃO}

O ceratômetro de Helmholtz permite a observação e a quantificação de torções oculares em indivíduos astigmatas através de metodologia inédita com modificações simples do equipamento.

\section{ABSTRACT}

Purpose: To develop a methodology to evaluate ocular torsion reflex. Methods: Modifications of a Helmholtz keratometer were made in order to perform keratometry in the primary position and during head tilt ( 30 degrees to the right, 30 degrees to the left). A total of 16 patients (32 eyes) were examined. There was a mean astigmatism of 0.50 to 3.50 (mean $1.18 \pm 0.61$ ). Results: The mean recorded intortions (right eye $5.31 \pm 4.23$, left eye $5.22 \pm 3.91$ ) were slightly lower than the extortions (right eye $7.84 \pm 4.79$, left eye $7.78 \pm 4.09$ ) with no significant difference between both eyes. Conclusions: The modified Helmholtz keratometer allows new and simple method to quantify ocular counterrolling.

Keywords: Astigmatism; Reflex, vestibulo-ocular; Eye movements; Torsion; Diagnostic ophthalmological techniques; Case report

\section{REFERÊNCIAS}

1. Hewitt RS. Torsional eye movements. Arch. Ophthalmol 1951;34:253-60.

2. Quereau JVD. Some aspects of torsion. Arch Ophthalmol 1954;51:783-4.

3. Quereau JVD. Rolling of the eye around its visual axis during normal ocular movements. Arch Ophthalmol 1955;53:807-10.

4. Ferman L, Collewijn H, Van Den Berg V. A direct test of listing's law - II. Human ocular torsion measured under dynamic conditions. Vision Res 1987; 27:939-51.

5. Allen MJ, Carter JH. The torsion component of near reflex. Am J Optom 1967;44:343-9.

6. Kushner BJ, Kraft S. Ocular torsional movements in normal humans. Am J Ophthalmol 1983;95:752-62.

7. Levine MH. Evolution of the Bielschovsky headtilt test. Arch Ophthalmol $1969 ; 82: 433$.

8. Jampel RS. Ocular torsion and the function of vertical extraocular muscles. Am J Ophtalmol 1975;79:292-304.

9. Prieto-Diaz J, Souza Dias C. Fisiologia dos movimentos oculares. In: PrietoDiaz J, Souza Dias C. Estrabismo 3 ed. Barcelona: Roca; 1996. P. 134-8

10. Curthoys IS, Moore ST, McCoy SG, Halmagyi GM, Markham CH, et al. VTM. A new method of measuring ocular torsion using image processing techniques. Ann N Y Acad Sci 1992;656:826-8.

11. Jampel RS. Ocular torsion and the primary retinal meridians. Am J Ophthalmol 1981;91:14-24. 